Journal of Engineering and Science Research 5 (5): 07-13, 2021

e-ISSN: 2289-7127

(C) RMP Publications, 2021

DOI: $10.26666 /$ rmp.jesr.2021.5.2

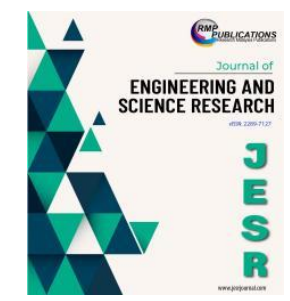

\title{
Green Mobile Application to Reduce Food Waste - Thrifteal
}

\author{
Syaimak Abdul Shukor and Farah Hanan Zulkafri \\ Center for Artificial Intelligence Technology, Faculty of Information Science \& Technology, \\ Universiti Kebangsaan Malaysia, 43600 UKM Bangi, Selangor, Malaysia.
}

\begin{abstract}
The Sustainable Development Goals (SDGs) are a blueprint for achieving a better and more sustainable future for all people and the world by 2030. It is a universal call for everyone to act in order to protect the earth and improve the lives and prospects of the world. A green mobile application has been developed in assisting the user to achieve various SDGs. This paper discusses developing a green mobile application - Thrifteal, which focuses on Sustainable Development Goal 12 in ensuring sustainable consumption and production patterns. In order to achieve Sustainable Development Goal 12, a detailed understanding is needed of how human food consumption affects the planet. According to the Secretary-General Sustainable Development Goals, worldwide material consumption has expanded rapidly, as the material footprint per capita jeopardises Sustainable Development Goal 12 more broadly. On another note, food waste is also indicated as the primary type of waste that goes into landfills. Therefore, the project's main idea is to overcome the food waste problem at the individual level by offering two modules that will contribute to a sustainable lifestyle, such as an expiry date tracker for short shelf-life food and food sharing. In addition, this application will be developed using the Android Studio software system and based on the Waterfall Methodology. This project aims to prevent users from throwing away food that is still in good condition and sharing food with the needy.
\end{abstract}

Keywords: Green Mobile Application, Sustainable Development Goals 12

\section{INTRODUCTION}

In this era of globalization, smartphones are considered a basic necessity in society in line with rapidly evolving technology. The use of applications via smartphones facilitates the activities of daily living in various forms, such as ordering food and buying necessities online. In addition, the application is also one of the modern alternatives in helping consumers solve multiple problems such as food wastage, loss of expiration date marks on food, and excessive purchase of cooking ingredients. Waste from food waste occurs widely and contributes to high methane gas production, thus harming our earth.

Meanwhile, most individuals are aware of the importance of a sustainable lifestyle such as recycling practices, food waste reduction, energy conservation and prudent waste disposal management. According to the United Nations (UN), the Sustainable Development
Goals (SDGs) are a universal call for human beings to protect the earth and improve the lives and prospects of every individual worldwide [1]. The member states of the United Nations adopted all 17 goals as part of the 2030 development goals agenda planned over a 15 -year period for all goals to be achieved. From another perspective, today, many mobile applications support the Sustainable Development Goals, such as the SDGs in Action application, which provides awareness and invites users to achieve each goal through the activities proposed by the application [1-2, 12].

Therefore, the development of the Food Waste Reduction Mobile Application - Thrifteal was introduced in this paper as a small step in an effort to create more effective sustainability to protect the earth. In addition, this project is inspired by the 2 nd Sustainable Development Goal, which is zero hunger and the 12th Sustainable Development Goal, which is sustainable consumption and production patterns.

Corresponding Author: Syaimak Abdul Shukor, Center for Artificial Intelligence Technology, Faculty of Information Science \& Technology, Universiti Kebangsaan Malaysia, 43600 UKM Bangi, Selangor, Malaysia. Email: syaimak@ukm.edu.my 
Therefore, to achieve both of the Sustainable Development Goals, a precise understanding of the process of human food consumption in influencing the planet is essential. According to UNDP Goodwill Ambassador Roca Brothers, "Food cannot be a threat to sustainability; instead, food is a source of sustainable development" [3]. Thoroughly, the practice of a sustainable lifestyle can contribute to achieving sustainable development goals and contribute to the well-being of the surrounding community.

The problems of the study are highlighted through the Report of the Secretary-General of the Sustainable Development Goals, which is the rapidly growing use of materials worldwide and the per capita material footprint that jeopardizes the achievement of the Sustainable Development Goals 12 and the overall Sustainable Development Goals. According to the Food and Agriculture Organization, food waste is also categorized as the primary type of waste that enters landfills. Meanwhile, the Malaysian Solid Waste Management Corporation (SWCorp) also stated that Malaysia generates 16,650 tonnes of food waste per day $[2,4$ - 6]. As such, the development of this application assists consumers in reducing food waste while encouraging food sharing with individuals in need [7 -8].

This project aims to develop a mobile green food waste reduction application with two main modules: shortlived food expiration date tracker and food sharing that helps individuals in Malaysia start a sustainable lifestyle without food waste. The developed apps aim to materialize that green mobile applications can assist in reducing food waste by sharing the food with others and by tracking the expiry date of food. This move is a small step in supporting Sustainable Development Goals 12 in ensuring sustainable food consumption.

\section{METHOD}

The Waterfall Methodology was used to develop the mobile green applications [9-11]. The development consist of five iterated phases: Planning Phase, Analysis Phase, Design Phase, Implementation Phase, and Testing and Maintenance Phase.

\subsection{Planning Phase}

All information and user specifications are gathered in the initial planning phase, and user problems are also identified. Each subsequent phase can be planned without interruption based on this important information until the project is completed.

\subsection{Analysis Phase}

In this phase, the needs and requirements of the green mobile applications will be identified. The features and modules that are required will be determined through a comprehensive analysis. The justification is, applications can be developed by meeting the needs and solving the problems of users. In addition, several methods are implemented in the analysis phase: preliminary studies through questionnaires, journal readings, and observation of existing green applications.

\subsection{Design Phase}

The design phase describes the project's overall development in terms of interface design up to the type of software involved. The process of drawing diagrams such as application flow chart diagrams and entity relationship diagrams (ERD) is accomplished in this phase. The user interface flow for this application is designed and orchestrated in this phase based on the user requirements.

\subsection{Implementation Phase}

In the implementation phase, mobile green application development and coding activities are initiated. All implementations are based on information and findings from the first phase to the third phase. Green mobile applications are developed using Android Studio software and Firebase services as application developers for data storage processes in real-time application databases. Java is a programming language used to develop applications. Once the application is developed, it is tested to see if it can function to identify any errors in advance.

\subsection{Testing and Maintenance Phase}

The testing and maintenance phase allows the mobile green application to be tested for adoption by potential users. If there are 'bugs' or insufficient features, improvements are made until the users are satisfied.

\section{RESULT AND DISCUSSION}

In this section, the developed green mobile application - Thrifteal, will be described in detail based on its user interface and the flow of the apps. Furthermore, the testing activities performed towards the developed apps are explained to describe the usability of the system flow and the syntax.

According to the apps development objectives, the results are about the concepts and ideas realized through coding activities to develop mobile green applications. Through the implementation phase, application development activities are carried out according to the needs and objectives of the app's requirements. In the meantime, the system interface is a 
display of applications and a medium of user-friendly interaction for users to facilitate the use of applications. The following is a general interface of applications developed for mobile green applications such as log and check-in modules, expiration date tracker modules and food sharing modules.

First, users must select the role either as provider or receiver during login, as shown in Figure 1. The selection is to make it easier for the end-user to focus on one main role. Next, the user is taken to the login interface, where the user has to enter details such as an email address and a password before logging in. If the user does not have an account, the user can directly press the sign-in button from the login interface.
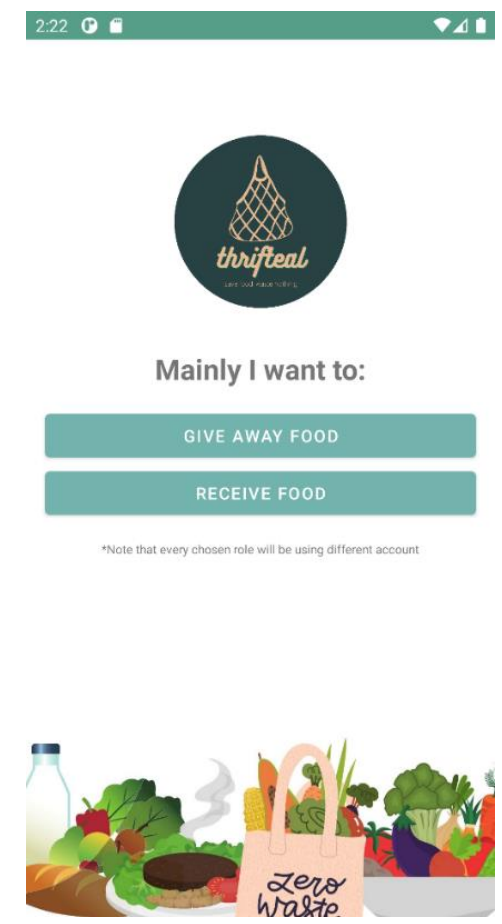

Figure 1: Main interface - selection of role by user

Figure 2 and Figure 3 show the login and check-in interface of the mobile green application as user and receiver.

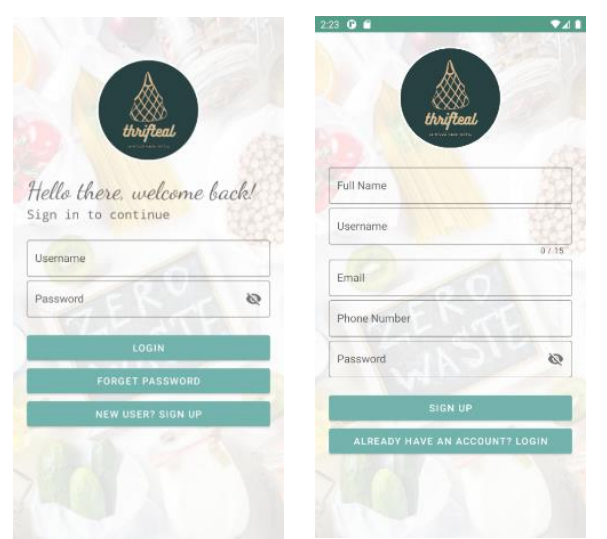

Figure 2: User Login Figure 3:Receiver Login

After the user who selects the receiver as the primary role successfully logs into the application, the user is taken to the main menu interface, where several main modules of the application can be selected, as in Figure 4 . The expiry date tracker is among the main modules, where users can track their food's expiry date. Next is the find food module; this is where the user can search for any available food to be given away.

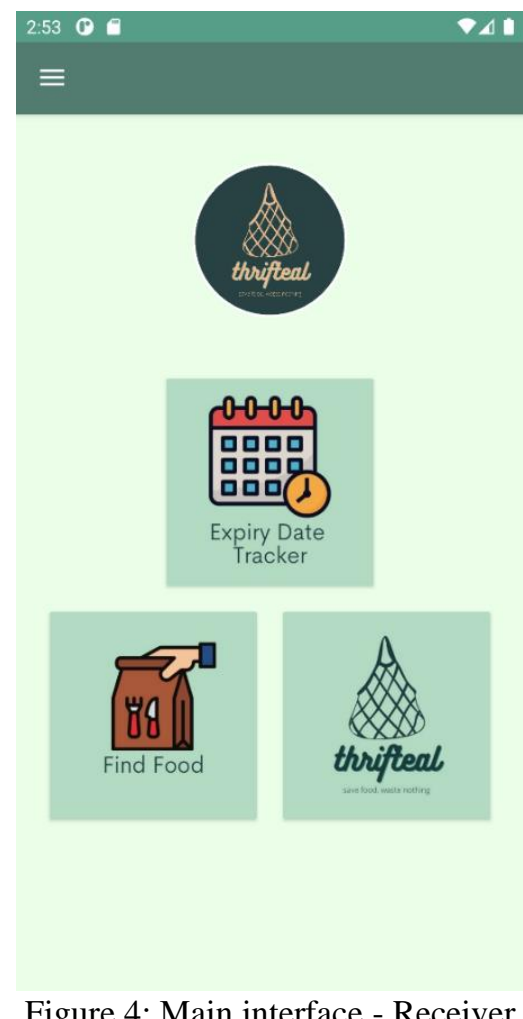

Figure 4: Main interface - Receiver

When the user presses the expiry date tracker button, the user interface will be displayed, such as in Figure 5. On this page, there is a list of foods along with 
information such as the expiration date. Users can update by selecting food from the list automatically and filling in the dates from the available calendar features.

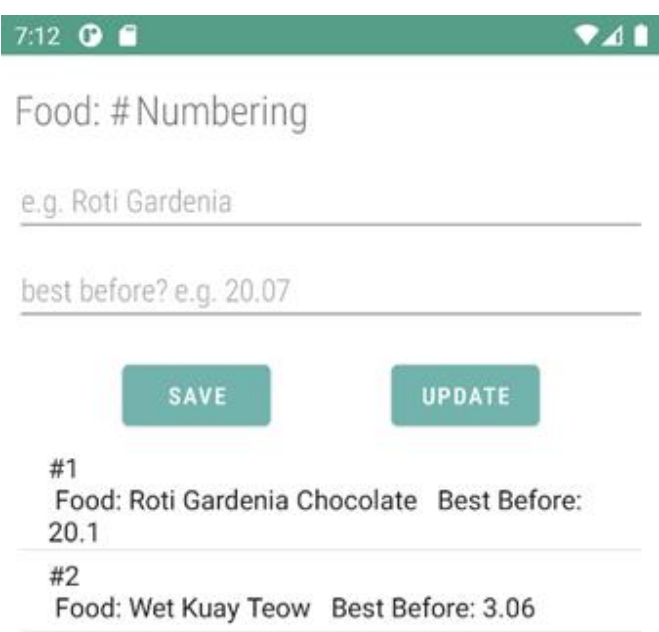

Figure 5: Expiration Date Tracker Interface

In addition, users can update food information or remove unrelated lists. To be able to perform this operation on this section, there is Local Storage, where each information will go into the local database. DAO (Data Access Objects) and entity are used to enable this activity to occur. DAO is a major class in which it defines application database interactions and encompasses various query methods.

In the next module, find food, the receiver can see all the foods uploaded by the provider in a list form. Users can request the food that they want by selecting the button that represents the food. Users can request the quantity of the food based on availability. As shown in Figure 6, information such as type of food, the picture of the food, amount, availability is provided to the user. Furthermore, the pick-up address of the requested food is also available for the receiver. Components such as FirebaseRecycler, Adapter, Holder are used to enable the inter-delivery of the related information to this page.

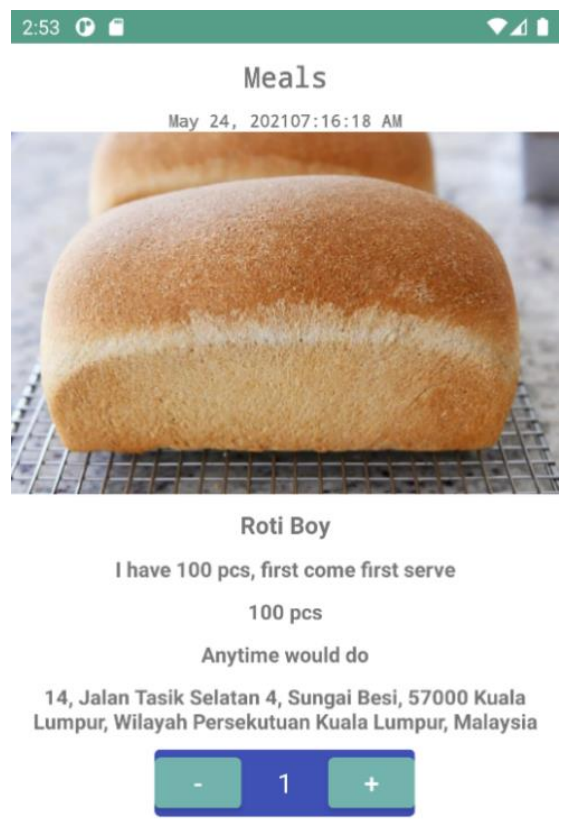

\section{REQUEST}

Figure 6: Food List and Selection

Next, Figure 7 shows the list of foods on the demand list that the receiver can view once they have selected and confirmed their food choices. While Figure 8 represents the user interface that reports the status of whether the provider has received the request for the food.

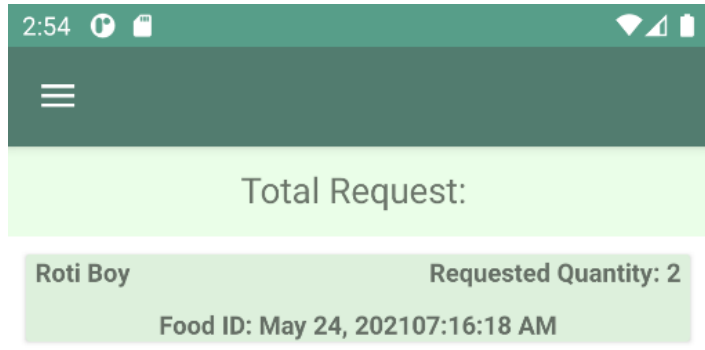

Figure 7: List of Food in Demand List 


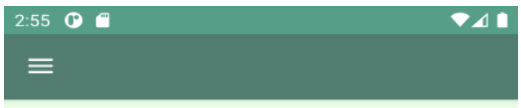

Request Status: Not Confirmed

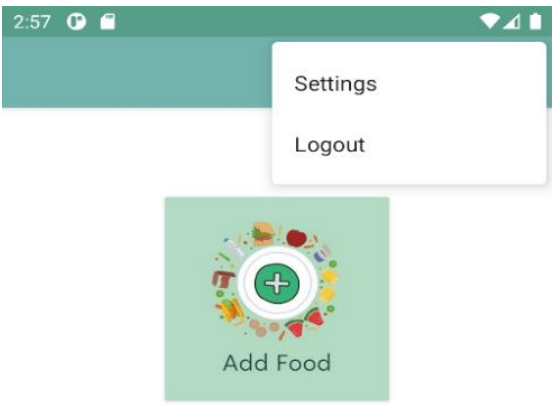

Your final food request has been sent successfully! We will notify the Giver for them to take action.

You can only request more food once (a) request :) Kindly wait with patience.

Figure 8: The Status of the Food Request

Subsequently, if the user decides to be the food provider, the user needs to select the giveaway food button, as shown in Figure 1. Next, the apps will bring to Figure 9 that shows the main interface when the user chooses to be a provider. Users can choose whether to add food or view the list of requests from other users (receiver). Figure 10 shows that when the user presses the add food button, the user has to select the food category. After that, the provider can upload the food information displayed on the receiver page, such as picture, quantity and location of food intake (mentioned in Figure 6). The provider can press the 'Locate Me' button to track the user's current whereabouts for locations retrieval. Figure 11 shows information that are required to be key-in when the provider decides to give away food. All information provided will be sent in realtime to the Firebase database.

Figure 9: Provider Interface

Add New Food

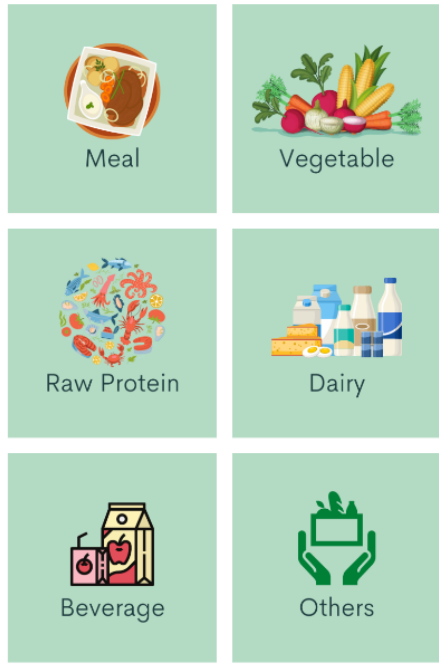

\section{EDIT FOOD}

Figure 10: Food Category 
Syaimak \& Farah/ Journal of Engineering and Science Research, 5(5) 2021, Pages: 07-13

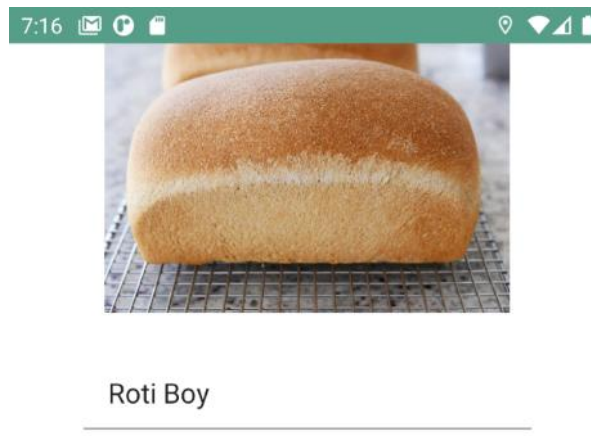

I have 100 pcs, first come first serve

\begin{tabular}{l}
$100 \mathrm{pcs}$ \\
\hline Anytime would do \\
\hline
\end{tabular}

14, Jalan Tasik Selatan 4, Sungai Besi, 57000 Kuala Lumpur, Wilayah Persekutuan Kuala Lumpur, Malaysia

\section{Locate Me}

Figure 11: Information of the Food to be Distributed or Give Away

In addition, the provider can also see all the list of food requests from other users and can inform the user about the status of the request via phone call or email. Then, the provider can also press the show the requested food button to change the status of the food request, whether it is accepted or rejected, as shown in Figure 12.

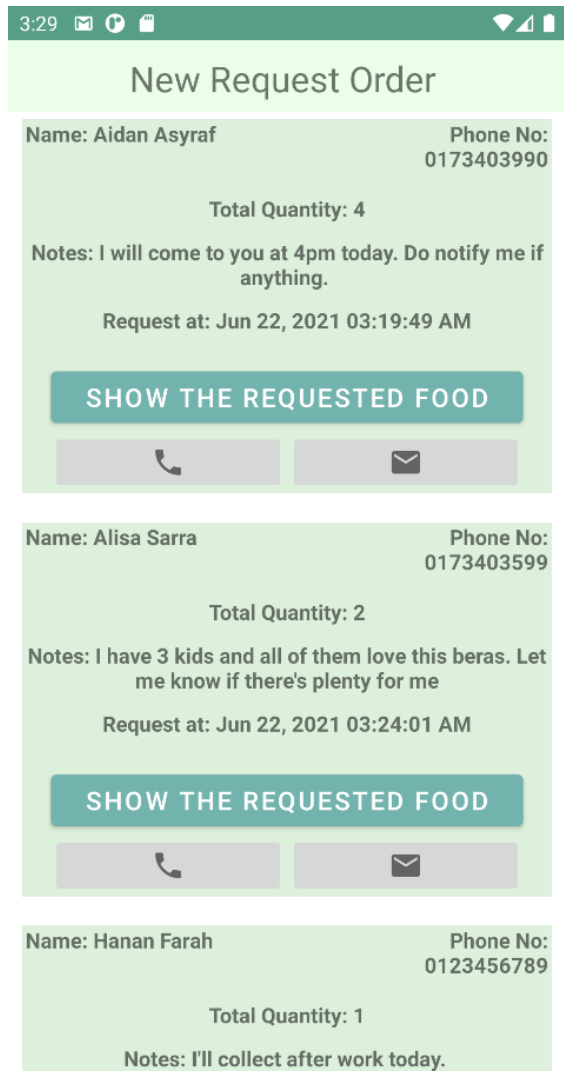

Figure 12: List of Food Request

In the next phase, in order to perceive the functionality and usability of the developed apps, a series of application system testing is being done towards the developed apps. Application system testing is a phase to test the effectiveness of applications in assisting users in reducing food waste. The testing phase is significant to ensure that the user's needs and requirements of green mobile applications are met and fulfilled. Several types of level testing can be done, such as integration, component, system, and acceptance.

For the developed green mobile application, the tests implemented are Functionality Testing and User Acceptance Testing. The purpose of both tests is to determine whether the application's requirements can be met and confidence in the application can be built, and evaluate its suitability for the end-user. 
Functional Testing plays a vital role in determining the effectiveness of each component and feature in a mobile green application. This testing is part of the Black Box Testing, where it is implemented to ensure that the developed application works according to the expected resolution. Each developed function or module must meet the objectives that have been set in the early part of the development phase. From this testing, all developed modules are functioning according to the purpose or requirement.

Next, User Acceptance testing is conducted through questionnaires for end-users after they have experienced the real developed apps. A total of thirteen respondents were selected to participate in the testing as end-users, and they comprised of various ages and backgrounds. According to the user acceptance testing questionnaire, 11 out of 13 users stated that they do not need help in using the application. This indicates that the application has an easy-to-understand interface. Meanwhile, most users think that the application has the expected functions and capabilities and that users believe that the application can reduce food waste among individuals. Overall, users are satisfied with the final concept of the developed application.

\section{CONCLUSION}

The development of mobile green applications was successfully implemented and achieved the objectives and requirements set in the project planning phase following the functional requirements. In the meantime, the application was developed with the hope of helping in reducing food waste among the general public. Overall, the green mobile applications developed can achieve the study's objectives in reducing food waste, thus leading to a more sustainable life. However, some improvements can be made in the future to ensure that the functionality of this green mobile application remains relevant to end-users.

\section{ACKNOWLEDGEMENTS}

The authors acknowledge the support from Universiti Kebangsaan Malaysia under the grant GGP-2017-018.

\section{REFERENCES}

[1] Food and Agriculture Organization. 2016. Sustainable Development Goals 12. http://www.fao.org/sustainable-developmentgoals/indicators/1231/en/ [28 Oktober 2020]

[2] Harian Metro. 2019. 16,650 tan sisa makanan dibuang setiap hari. https://www.hmetro.com.my/mutakhir/2019/04/4 45042/16650-tan-sisa-makanan-dibuang-setiaphari_[28 Oktober 2020]
[3] Huffpost. 2016. Food with Soul: A Recipe for Sustainable Development. https://www.huffpost.com/entry/food-with-soul-arecipe-f_b_9081576 [28 Oktober 2020]

[4] Farahi Kamaruddin. 2018. Jaminan Makanan (Food Security) di Malaysia. https://www.thepatriots.asia/jaminan-makananfood-security-di-malaysia/ [30 Oktober 2020]

[5] FoodWise. 2020. https://foodwiseapp.com/ [31 Oktober 2020]

[6] SWCorp. 2019. Bertan-Tan Makanan Elok Dibuang. https://www.swcorp.gov.my/bertan-tan-makananelok-dibuang/ [28 Oktober 2020]

[7] Prof Dato Roshada Hashim, Noor Khalidah Abdul Hamid. 2020. Tackling food insecurity in the midst of food security. https://www.nst.com.my/opinion/columnists/2020 /05/592533/tackling-food-insecurity-midst-foodsecurity [29 Oktober 2020]

[8] Prof Datuk Dr M Nasir Shamsudin. 2019. Food Insecurity: Coping Strategies And Policy Responds.https://www.upm.edu.my/artikel/food_i nsecurity_coping_strategies_and_policy_responds -53445 [30 Oktober 2020]

[9] Nghiem T. P. L \& Carrasco L. R. 2016. Mobile Applications to Link Sustainable Consumption with Impacts on the Environment and Biodiversity. Vol. 66, No. 5, hlm. 384392.https://www.jstor.org/stable/90007595?seq=1 [31 Oktober 2020]

[10] Pranathi Badugu. 2018. Software Engineering and Architectural Design. https://www.geeksforgeeks.org/softwareengineering-architectural-design/ [10 December 2020]

[11] Visual Paradigm. 2019. What is Sequence Diagram?https://www.visualparadigm.com/guide/uml-unified-modelinglanguage/what-is-sequence-diagram/ December 2020]

[12] Apostolidis, C., Brown, D., Wijetunga, D., Kathriarachchi, 2021. Sustainable Value CoCreation at the Bottom of the Pyramid: Using Mobile Applications to Reduce Food Waste and Improve Food Security. Journal of Marketing Management, Vol. 37 [9-10], 856-886. 